\title{
Modified Wilkinson Power Divider Using Transmission Lines for Various Terminated Impedances and an Arbitrary Power Ratio
}

\author{
Young-Chul Yoon ${ }^{1} \cdot$ Young Kim,
}

\begin{abstract}
This paper introduces a modified Wilkinson power divider that uses uniform transmission lines for various terminated impedances and an arbitrary power ratio. For the designed power ratio, the proposed divider changes only the electrical lengths of the transmission lines between the input and output ports, and those between the output ports and the isolation resistor. In this case, even when various termination impedances of the ports exist, the divider characteristics are satisfied. To verify the feasibility of the proposed divider, two circuits were designed to operate at a frequency of $2 \mathrm{GHz}$ with 2:1 and 4:1 power splitting ratios and various terminated impedances of 40, 70, and 60 $\Omega$ for one circuit, and 50,70, and $60 \Omega$ for the other. The measurement and simulation results were in good agreement.
\end{abstract}

Key Words: Arbitrary Power Ratio, Unequal Divider, Uniform Transmission Line, Various Terminated Impedance, Wilkinson Divider.

\section{INTRODUCTION}

The divider is the most widely used passive component in the wireless industry. In many cases, the same splitting divider is used $[1,2]$. However, in special applications, cases that require unequal distribution $[3,4]$ or various termination impedances $[5,6]$ exist. To achieve a divider with unequal or various terminated impedances, a high-impedance transmission line must be implemented. Such a high-impedance transmission line is difficult to implement because of its very narrow line width that must be implemented through microstrip technology. Moreover, to satisfy the characteristics of the high-impedance line, a bulky capacitor or coupled lines with narrow gaps are used.

Recently, a new design method has been proposed to adjust only the electrical length of the transmission lines between the input and output ports, or between the output ports and the isolation resistor, to achieve the operation of an unequal divider. Many dividers using a uniform transmission line have been introduced, such as a divider with uniform transmission lines of various electrical lengths [7-9], a structure using an isolated resistor with open-stub connection to obtain enhanced bandwidth [10], an isolated resistor configuration connected to the same impedance lines between the output ports with long stub length [11], a structure connected to various impedance lines at both sides of an isolation resistor [12], a Gysel divider with a phase shifter instead of a $180^{\circ}$ transmission line [13], a ring hybrid coupler with a 50- $\Omega$ transmission line [14], and a half mode substrate integrated waveguide (HMSIW) divider with composite right and left-handed transmission line (CRLH-TL) [15]. This type of splitter uses a transmission line with uniform impedance, and

\footnotetext{
Manuscript received July 10, 2018 ; Revised October 3, 2018 ; Accepted October 30, 2018. (ID No. 20180710-053J)

${ }^{1}$ Department of Electronics Engineering, Catholic Kwandong University, Gangneung, Korea.

${ }^{2}$ School of Electronics Engineering, Kumoh National Institute of Technology, Gumi, Korea.

"Corresponding Author: Young Kim (e-mail: youngk@kumoh.ac.kr)
}

This is an Open-Access article distributed under the terms of the Creative Commons Attribution Non-Commercial License (http://creativecommons.org/licenses/by-nc/4.0) which permits unrestricted non-commercial use, distribution, and reproduction in any medium, provided the original work is properly cited.

(c) Copyright The Korean Institute of Electromagnetic Engineering and Science. All Rights Reserved. 
it does not use an impedance transformer to match each port, even though it operates as an unequal divider. Such a divider consists of circuits with an arbitrary power split ratio and a termination impedance of $50 \Omega$.

In this paper, we propose a modified Wilkinson divider using a uniform transmission line with various termination impedances and an arbitrary dividing ratio as well as the previously used $50 \Omega$ termination impedance. This type of device eliminates the requirement for a matching circuit between the divider and the peripheral device with various termination impedances, and allows a small circuit size to be achieved.

\section{THEORY AND DESIGN}

Fig. 1 shows the schematic of the proposed power divider with power splitting ratio $k^{2}\left(=P_{2} / P_{3}\right)$. This proposed divider consists of three transmission lines with uniform impedance $Z_{u L}$ and various electrical lengths of $\theta_{1 L}, \theta_{2 L}$, and $\theta_{3 L}$, an isolation resistor $R_{i s o}$, and various terminated impedances of $R_{a T}, R_{b T}$, and $R_{c T}$.

In addition, this divider must satisfy the $S$-parameter characteristics of the unequal Wilkinson power divider:

$$
(S)_{\text {unequal }}=\frac{1}{\sqrt{1+k^{2}}}\left(\begin{array}{ccc}
0 & k \cdot e^{-j \beta} & e^{-j \beta} \\
k \cdot e^{-j \beta} & 0 & 0 \\
e^{-j \beta} & 0 & 0
\end{array}\right)
$$

where $\beta$ is the phase shift of the transmission coefficient.

Because the proposed power divider with various terminated impedances is asymmetrical, we analyzed it using scattering parameters rather than the conventional even-odd method. When port 1 is excited, all power is transmitted to the output ports, $P_{2}$ and $P_{3}$, and the voltage from the branch of $P_{1}-P_{2}$ to ground is the same as that from the branch of $P_{1}-P_{3}$ to ground at any distance from $P_{1}$, and no current flows in the isolation resistor. Because the isolation resistor operates as an open circuit, we can design an equivalent circuit between ports 2 and 3 , as shown in Fig. 2(a). The ABCD parameters between port 1 and ports 2 and 3 can be expressed as

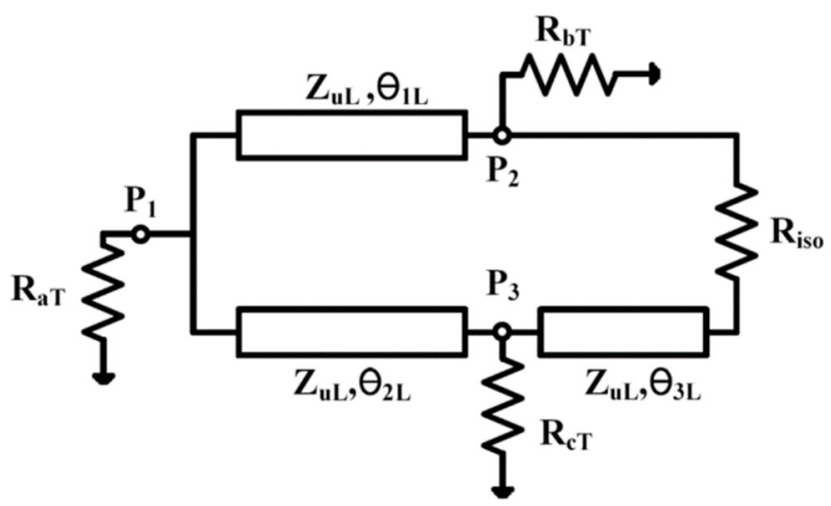

Fig. 1. Schematic of the proposed Wilkinson power divider.

$$
\begin{gathered}
\left(\begin{array}{ll}
A_{21} & B_{21} \\
C_{21} & D_{21}
\end{array}\right)=\left(\begin{array}{cc}
\cos \theta_{1 L} & j Z_{u L} \cdot \sin \theta_{1 L} \\
\frac{j \sin \theta_{1 L}}{Z_{u L}} & \cos \theta_{1 L}
\end{array}\right) \\
\left(\begin{array}{ll}
A_{31} & B_{31} \\
C_{31} & D_{31}
\end{array}\right)=\left(\begin{array}{cc}
\cos \theta_{2 L} & j Z_{u L} \cdot \sin \theta_{2 L} \\
\frac{j \sin \theta_{2 L}}{Z_{u L}} & \cos \theta_{2 L}
\end{array}\right)\left(\begin{array}{cc}
1 & 0 \\
\frac{j \tan \theta_{3 L}}{Z_{u L}} & 1
\end{array}\right)
\end{gathered}
$$

The ABCD parameters of Eqs. (2) and (3) can be converted into the $S$-parameters of $S_{21}$ and $S_{31}$. Using the relation of $S_{21}=k \cdot S_{31}$, the following related equations are then obtained.

$$
\begin{aligned}
& k^{2} \sqrt{\frac{R_{c T}}{R_{b T}}} \cdot\left(R_{b T}+\frac{1+k^{2}}{k^{2}} R_{a T}\right) \cos \theta_{1 L} \\
&=\left\{R_{c T}+\left(1+k^{2}\right) R_{a T}\right\} \cos \theta_{2 L}-R_{c T} \sin \theta_{2 L} \tan \theta_{3 L} \\
& k^{2} \sqrt{\frac{R_{c T}}{R_{b T}}} \cdot\left(Z_{u L}^{2}+\frac{1+k^{2}}{k^{2}} R_{a T} R_{b T}\right) \sin \theta_{1 L} \\
&=\left\{Z_{u L}^{2}+\left(1+k^{2}\right) R_{a T} R_{c T}\right\} \sin \theta_{2 L}+\left(1+k^{2}\right) R_{a T} R_{c T} \cos \theta_{2 L} \tan \theta_{3 L}
\end{aligned}
$$

In Fig. 2(a), under the input matching condition $\left(S_{11}=0\right)$, we have

$$
\begin{gathered}
\frac{1}{Z_{2 e}}+\frac{1}{Z_{3 e}}=\frac{1}{R_{a T}} \\
Z_{2 e}=Z_{u L} \frac{R_{b T}+j Z_{u L} \tan \theta_{1 L}}{Z_{u L}+j R_{b T} \tan \theta_{1 L}}
\end{gathered}
$$

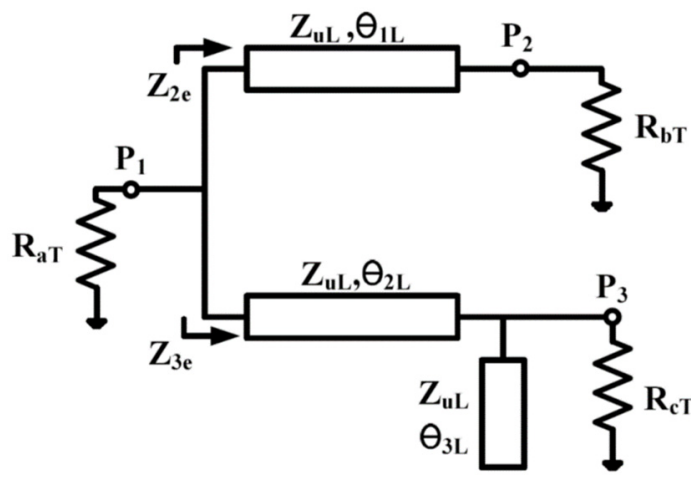

(a)

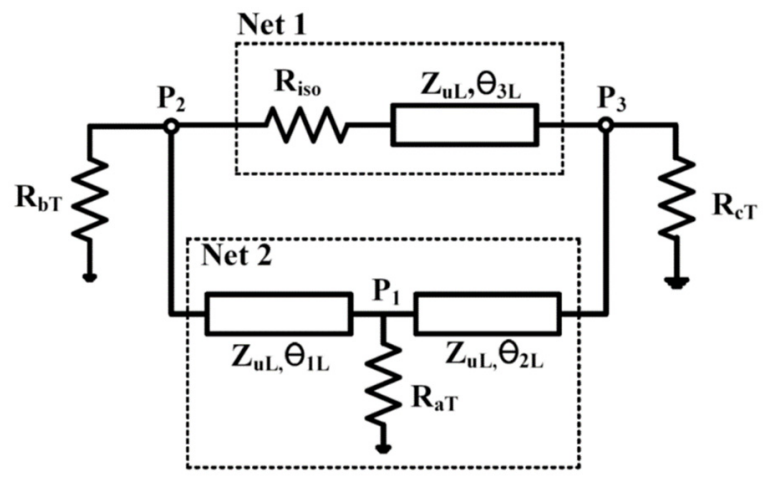

(b)

Fig. 2. (a) Equivalent circuit of proposed divider when port 1 is excited and (b) equivalent circuit of the proposed divider when port 2 is excited. 


$$
Z_{3 e}=Z_{u L} \frac{R_{c T}\left(1-\tan \theta_{2 L} \tan \theta_{3 L}\right)+j Z_{u L} \tan \theta_{2 L}}{Z_{u L}+j R_{c T}\left(\tan \theta_{2 L}+\tan \theta_{3 L}\right)}
$$

where $Z_{2 e}$ and $Z_{3 e}$ are the input impedances of the upper and lower branches, respectively.

Based on the principle of conservation of energy and ideal transmission lines, the real parts of $Z_{2 e}$ and $Z_{3 e}$ are expressed as follows:

$$
\begin{gathered}
\operatorname{Re}\left[Z_{2 e}\right]=\frac{1+k^{2}}{k^{2}} R_{a T} \\
\operatorname{Re}\left[Z_{3 e}\right]=\left(1+k^{2}\right) R_{a T}
\end{gathered}
$$

In Fig. 2(b), when port 2 is excited, the networks of Net1 and Net2 are connected in parallel, in which Net1 consists of the isolation resistor $R_{\text {iso }}$ and the transmission line of electrical length $\theta_{3 L}$; and Net 2 consists of a termination resistor $R_{a T}$ and transmission lines of electrical lengths $\theta_{1 L}, \theta_{2 L}$. The ABCD parameters of Net1 and Net 2 can be expressed as:

$$
\begin{aligned}
&\left(\begin{array}{ll}
A_{N e t 1} & B_{\text {Net } 1} \\
C_{\text {Net } 1} & D_{\text {Net } 1}
\end{array}\right)=\left(\begin{array}{cc}
1 & R_{i s o} \\
0 & 1
\end{array}\right)\left(\begin{array}{cc}
\cos \theta_{3 L} & j Z_{u L} \sin \theta_{3 L} \\
\frac{j \sin \theta_{3 L}}{Z_{u L}} & \cos \theta_{3 L}
\end{array}\right) \\
&\left(\begin{array}{ll}
A_{N e t 2} & B_{\text {Net } 2} \\
C_{\text {Net } 2} & D_{\text {Net } 2}
\end{array}\right)=\left(\begin{array}{cc}
\cos \theta_{1 L} & j Z_{u L} \sin \theta_{1 L} \\
\frac{j \sin \theta_{1 L}}{Z_{u L}} & \cos \theta_{1 L}
\end{array}\right)\left(\begin{array}{cc}
1 & 0 \\
\frac{1}{R_{a T}} & 1
\end{array}\right) \\
&\left(\begin{array}{cc}
\cos \theta_{2 L} & j Z_{u L} \sin \theta_{2 L} \\
\frac{j \sin \theta_{2 L}}{Z_{u L}} & \cos \theta_{2 L}
\end{array}\right)
\end{aligned}
$$

The ABCD parameters of Eqs. (11) and (12) are converted into the $Y$-parameters of Net1 and Net2, respectively, and the admittance parameters of the entire network can be obtained as follows:

$$
\left(\begin{array}{ll}
y_{11 \_t o t} & y_{12 \_t o t} \\
y_{21 \_t o t} & y_{22 \_t o t}
\end{array}\right)=\left(\begin{array}{ll}
y_{11 \_N e t 1} & y_{12 \_N e t 1} \\
y_{21 \_N e t 1} & y_{22 \_N e t 1}
\end{array}\right)+\left(\begin{array}{ll}
y_{11 \_N e t 2} & y_{12 \_N e t 2} \\
y_{21 \_N e t 2} & y_{22 \_N e t 2}
\end{array}\right)
$$

where

$$
y_{11_{-} t o t}=\frac{\cos \theta_{3 L}}{R_{i s o} \cos \theta_{3 L}+j Z_{u L} \sin \theta_{3 L}}+\frac{\cos \theta_{1 L} \cos \theta_{2 L}-\sin \theta_{1 L} \sin \theta_{2 L}+j \frac{z_{u L}}{R_{a T}} \sin \theta_{2 L} \cos \theta_{1 L}}{-\frac{z_{u L}^{2}}{R_{a T}} \sin \theta_{1 L} \sin \theta_{2 L}+j Z_{u L}\left(\sin \theta_{2 L} \cos \theta_{1 L}+\sin \theta_{1 L} \cos \theta_{2 L}\right)},
$$

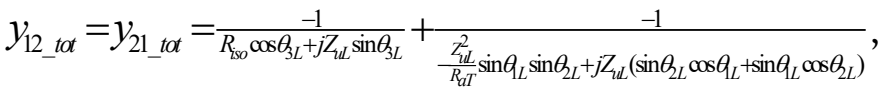$$
y_{22_{-} \text {tot }}=\frac{\cos \theta_{3 L}+j \frac{R_{i s o}}{Z_{u L}} \sin \theta_{3 L}}{R_{i s o} \cos \theta_{3 L}+j Z_{u L} \sin \theta_{3 L}}+\frac{\cos \theta_{1 L} \cos \theta_{2 L}-\sin \theta_{1 L} \sin \theta_{2 L}+j \frac{z_{u L}}{R_{a T}} \sin \theta_{1 L} \cos \theta_{2 L}}{\frac{z_{u L}^{2}}{R_{a T}} \sin \theta_{1 L} \sin \theta_{2 L}+j Z_{u L}\left(\sin \theta_{2 L} \cos \theta_{1 L}+\sin \theta_{1 L} \cos \theta_{2 L}\right)} .
$$

The admittance parameters of Eq. (13) can be converted to the $S$-parameters of $S_{22}, S_{32}$, and $S_{33}$ with terminated impedances of $R_{b T}$ and $R_{c T}$. The $S$-parameters of the entire network between ports 2 and 3 can be expressed as

$$
S_{22}=-\frac{\left(y_{11 \_t o t}-\frac{1}{R_{b T}}\right)\left(y_{22 \_t o t}+\frac{1}{R_{C C}}\right)-\mathrm{y}_{12 \_t o t} \cdot y_{21 \_t o t}}{\left(y_{11 \_t o t}+\frac{1}{R_{b T}}\right)\left(y_{22 \_t o t}+\frac{1}{R_{C T}}\right)-\mathrm{y}_{12 \_t o t} \cdot y_{21 \_t o t}}
$$

$$
\begin{aligned}
& S_{32}=-\frac{2 \sqrt{\frac{1}{R_{b T}} \cdot \frac{1}{R_{C T}}} \cdot \mathrm{y}_{21}{ }_{\text {tot }}}{\left(y_{11 \_t o t}+\frac{1}{R_{b T}}\right)\left(y_{22} \text { tot }+\frac{1}{R_{C T} T}\right)-\mathrm{y}_{12 \_-t o t} \cdot y_{21} \text { tot }} \\
& S_{33}=-\frac{\left(y_{11 \_t o t}+\frac{1}{R_{b T}}\right)\left(y_{22 \_t o t}-\frac{1}{R_{c T} T}\right)-\mathrm{y}_{12 \_t o t} \cdot y_{21 \_t o t}}{\left(y_{11 \_t o t}+\frac{1}{R_{b T}}\right)\left(y_{22 \_t o t}+\frac{1}{R_{C T} T}\right)-\mathrm{y}_{12 \_t o t} \cdot y_{21 \_t o t}}
\end{aligned}
$$

Based on Eqs. (4) to (5), (9) to (10), and (14) to (16), the electrical lengths $\theta_{1 L}, \theta_{2 L}, \theta_{3 L}$, and isolation resistance $R_{\text {iso }}$ that satisfy the power divider characteristic conditions with $\left|S_{22}\right|<-20 \mathrm{~dB}$, $\left|S_{33}\right|<-20 \mathrm{~dB}$, and $\left|S_{32}\right|<-20 \mathrm{~dB}$ at center frequency can be obtained by using MATLAB.

\section{SIMULATION AND EXPERIMENTAL RESULTS}

To validate the proposed power divider, we designed two types of circuits at a center frequency of $2 \mathrm{GHz}$. One has a power dividing ratio of $k^{2}=2$ and port impedances of $R_{a T}=40 \Omega, R_{b T}=$ $70 \Omega$, and $R_{c T}=60 \Omega$. The second circuit has a power dividing ratio of $k^{2}=4$ and port impedances of $R_{a T}=50 \Omega, R_{b T}=70 \Omega$, and $R_{c T}=60 \Omega$. For the first circuit, when the transmission line characteristic impedance of $Z_{u L}=40 \Omega$ was chosen, we calculated the electrical lengths and isolation resistance using the equations above and after optimization as follows: $\theta_{1 L}=157^{\circ}, \theta_{2 L}=146^{\circ}$, $\theta_{3 L}=47^{\circ}$, and $R_{\text {iso }}=12 \Omega$. For the second circuit, when a transmission line characteristic impedance of $Z_{u L}=40 \Omega$ was chosen, we calculated the electrical lengths and isolation resistance using the equations above and after optimization as follows: $\theta_{1 L}=153^{\circ}$, $\theta_{2 L}=130^{\circ}, \theta_{3 L}=66^{\circ}$, and $R_{i s o}=20 \Omega$. The Teflon substrate of the proposed power divider had a dielectric constant of 2.5 , a thickness of $0.787 \mathrm{~mm}$, and a conductor thickness of $0.035 \mathrm{~mm}$.

The simulation was performed using Microwave Office software with version 13 developed by National Instruments.

Fig. 3(a) and (b) show the photographs of the circuits in which $k^{2}=2$ and $k^{2}=4$, respectively, where power dividers of various port impedances and uniform transmission lines are implemented. For the measurement, the impedance transformers shown in Fig. 3 were used to match the input and output ports to $50 \Omega$.

Fig. 4(a) and (b) show the measured and simulated $S$-parameters of the circuit with a power dividing ratio of $k^{2}=2$ and port impedances of 40, 70, and $60 \Omega$; the figures show insertion losses of $\left|S_{21}\right|=2.0 \mathrm{~dB}$ and $\left|S_{31}\right|=5.0 \mathrm{~dB}$, an isolation of $\left|S_{32}\right|>25 \mathrm{~dB}$, an input return loss of $\left|S_{11}\right|$ that is better than $-20 \mathrm{~dB}$, and output return losses of $\left|S_{22}\right|,\left|S_{33}\right|$ that are better than $-18 \mathrm{~dB}$ at the center frequency of $2 \mathrm{GHz}$. In addition, Fig. 5(a) and (b) show the measured and simulated $S$-parameters of the circuit with a power dividing ratio of $k^{2}=4$ and port impedances of 50,70 , and $60 \Omega$; the figures show insertion losses of $\left|S_{21}\right|=1.2$ $\mathrm{dB}$ and $\left|S_{31}\right|=6.8 \mathrm{~dB}$, an isolation of $\left|S_{32}\right|>25 \mathrm{~dB}$, an input return loss of $\left|S_{11}\right|$ that is better than $-25 \mathrm{~dB}$, and out- 


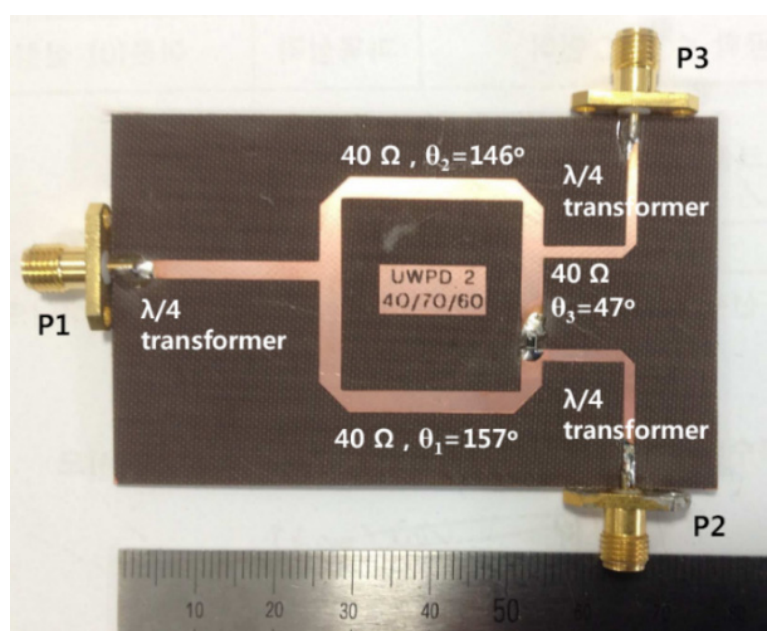

(a)

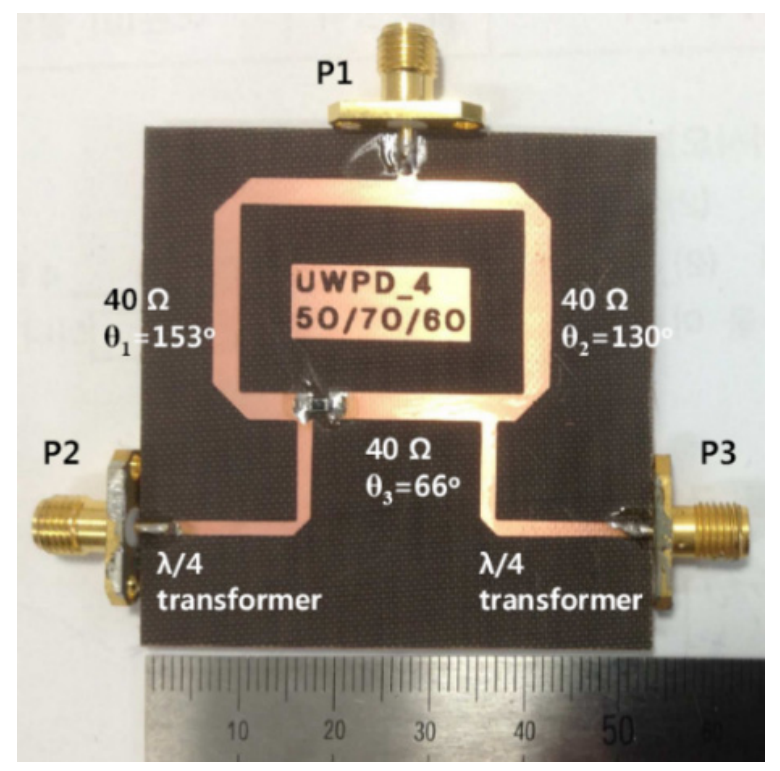

(b)

Fig. 3. Photographs of the implemented power divider: (a) $k^{2}=2$ and (b) $k^{2}=4$.

put return losses of $\left|S_{22}\right|,\left|S_{33}\right|$ that are better than $-25 \mathrm{~dB},-13$ $\mathrm{dB}$, respectively, at the center frequency of $2 \mathrm{GHz}$. In Figs. 4

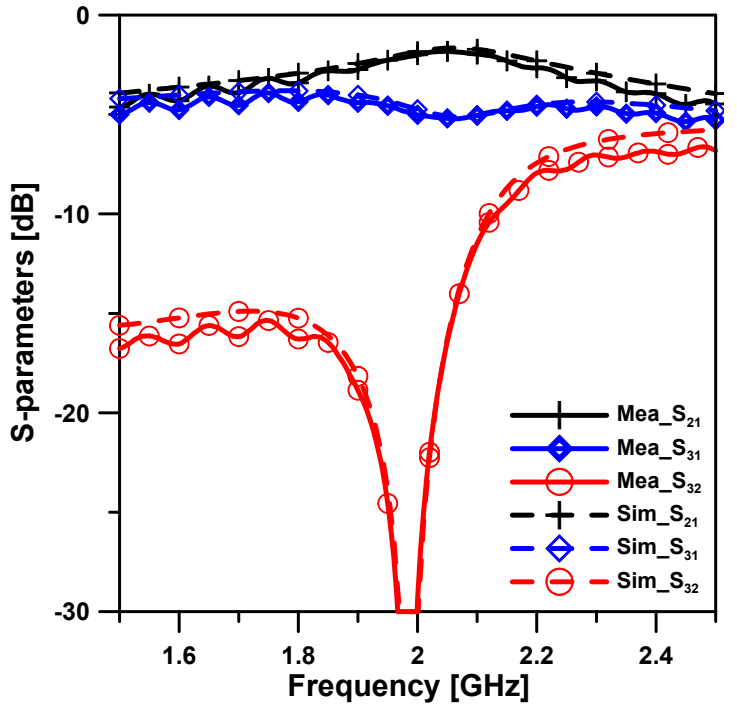

(a)

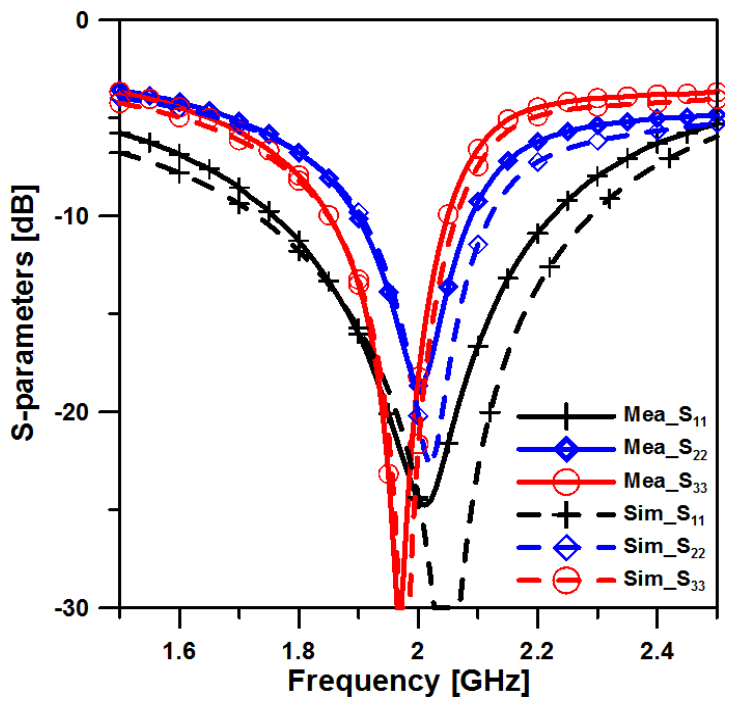

(b)

Fig. 4. Measured and simulated $S$-parameters of the $k^{2}=2$ circuit: (a) $\left|S_{21}\right|,\left|S_{31}\right|,\left|S_{32}\right|$ and (b) $\left|S_{11}\right|,\left|S_{22}\right|,\left|S_{33}\right|$.

and 5, the $\left|S_{33}\right|$ data can be observed with slight frequency deviation, which is caused by the parallel admittance of electrical

Table 1. Comparison of the proposed divider with conventional power dividers

\begin{tabular}{|c|c|c|c|c|c|c|c|c|}
\hline Ref. & $\begin{array}{l}\text { Dividing ratio } \\
\text { and type }\end{array}$ & $\begin{array}{c}\text { Frequency } \\
(\mathrm{GHz})\end{array}$ & $\begin{array}{c}\text { Total length } \\
\left({ }^{\circ}\right)\end{array}$ & $\begin{array}{c}\text { TL impedance } \\
(\Omega)\end{array}$ & $\begin{array}{l}\text { Term. } \\
(\Omega)\end{array}$ & $\begin{array}{c}\text { IL } \\
(\mathrm{dB})\end{array}$ & $\begin{array}{l}\text { RL } \\
(\mathrm{dB})\end{array}$ & $\begin{array}{l}\text { Isolation } \\
(\mathrm{dB})\end{array}$ \\
\hline [7] & 2:1 / 4:1 (WPD) & 1 & $270 / 300$ & 70.7 & 50 & 0.3 & 30 & 30 \\
\hline$[10]$ & 4:1 (WPD) & 3 & 388 & 50 & 50 & 0.9 & 15 & 20 \\
\hline [11] & 1:1 (WPD) & $60 / 90$ & 321.04 & 50 & 50 & 0.3 & 22 & 19 \\
\hline [12] & 2:1 / 4:1 / 9:1 (WPD) & 3 & 324.82 / $332.21 / 341.66$ & 50 & 50 & - & 20 & 20 \\
\hline [13] & 9:1 (Gysel) & 1 & 219 & 70.7 & 50 & 0.2 & 20 & 29 \\
\hline$[14]$ & 9:1 (Ring) & 1 & 378.6 & 50 & 50 & 0.4 & 25 & 40 \\
\hline This work & 2:1 / 4:1 (WPD) & 2 & $350 / 349$ & 40 & $40 / 50 / 60 / 70$ & 0.3 & 18 & 25 \\
\hline
\end{tabular}

$\mathrm{WPD}=$ Wilkinson power divider, $\mathrm{IL}=$ insertion loss, $\mathrm{RL}=$ return loss.

${ }^{a}$ Without output matching transformer. 


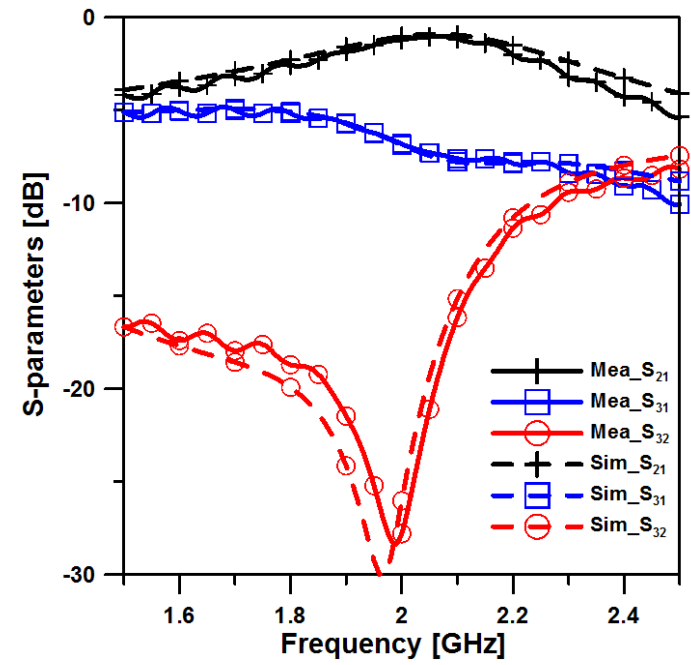

(a)

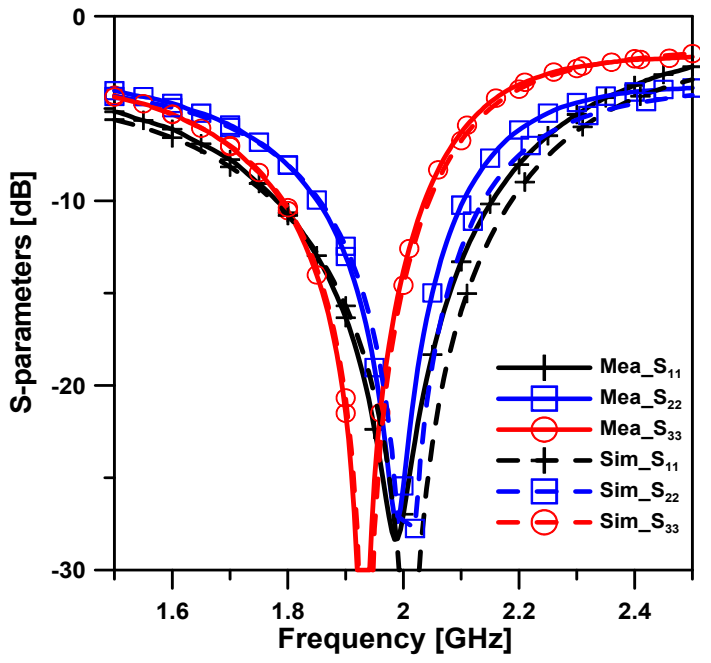

(b)

Fig. 5. Measured and simulated $S$-parameters of the $k^{2}=4$ circuit: (a) $\left|S_{21}\right|,\left|S_{31}\right|,\left|S_{32}\right|$ and (b) $\left|S_{11}\right|,\left|S_{22}\right|,\left|S_{33}\right|$.

Table 2. Summary of experimental results and design parameters of the proposed power divider

\begin{tabular}{cccccccccccc}
\hline Dividing ratio & Term. $(\Omega)$ & $\left|S_{21}\right|(\mathrm{dB})$ & $\left|S_{31}\right|(\mathrm{dB})$ & $\left|S_{11}\right|(\mathrm{dB})$ & $\left|S_{22}\right|(\mathrm{dB})$ & $\left|S_{33}\right|(\mathrm{dB})$ & $\left|S_{32}\right|(\mathrm{dB})$ & $\theta_{1}\left({ }^{\circ}\right)$ & $\theta_{2}\left(^{\circ}\right)$ & $\theta_{3}\left({ }^{\circ}\right)$ & $\mathrm{R}_{\text {iso }}(\Omega)$ \\
\hline 2 & $40 / 70 / 60$ & 2.0 & 5.0 & -20 & -18 & -18 & -25 & 157 & 146 & 47 & 12 \\
4 & $50 / 70 / 60$ & 1.2 & 6.8 & -25 & -25 & -13 & -25 & 153 & 130 & 66 & 20 \\
\hline
\end{tabular}

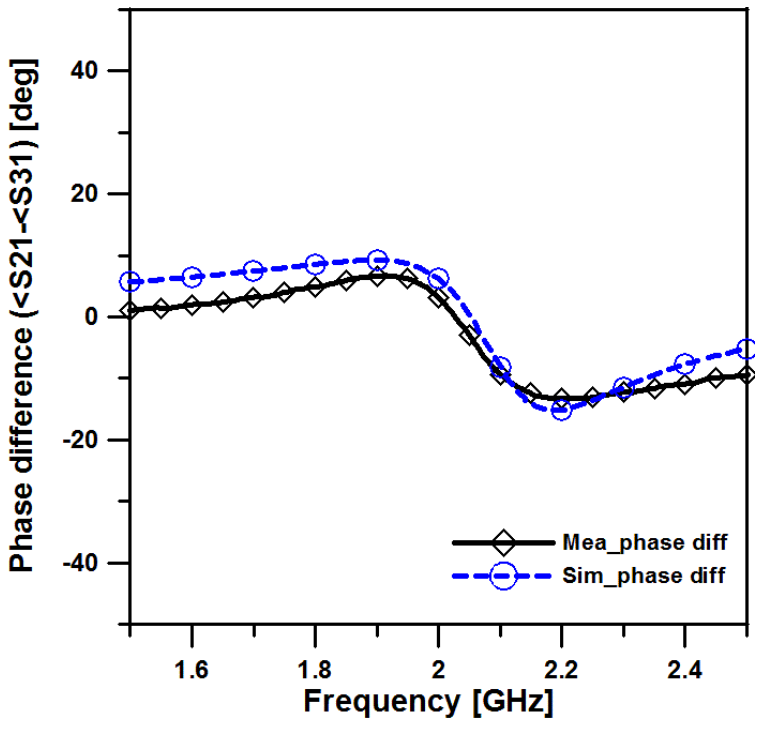

Fig. 6. Measured and simulated phase difference between the output ports of the $k^{2}=2$ circuit.

length $\theta_{3 L}$. Fig. 6 shows that the phase difference between the output ports of the $k^{2}=2$ circuit is $+3^{\circ}$ at the center frequency of 2 $\mathrm{GHz}$. Table 1 shows a comparison of dividers using the conventional uniform transmission line and the results obtained for the proposed divider. In addition, Table 2 summarizes the experimental results and design parameters of the proposed power divider.

\section{CONCLUSION}

This paper presented a modified Wilkinson divider using uniform transmission lines for various terminated impedances and an arbitrary dividing ratio. With this configuration, the desired splitting ratio can be obtained by adjusting only the electrical length of the transmission lines between the ports. Moreover, it has the advantage that the impedance of the ports is set to various terminated impedances, and is connected to a circuit without a matching circuit. The feasibility of the proposed power divider design concept was demonstrated, and the simulated and measured results were confirmed to be in good agreement.

\section{REFERENCES}

[1] E. J. Wilkinson, "An N-way hybrid power divider," IRE Transaction on Microwave Theory and Techniques, vol. 8, no. 1, pp. 116-118, 1960.

[2] U. H. Gysel, "A new N-way power divider/combiner suitable for high-power application," in Proceedings of IEEE MTT-S International Microwave Symposium, Palo Alto, CA, 1975, pp. 116-118.

[3] Y. Kim and Y. C. Yoon, "A modified unequal power divider with a complex isolation component for enhanced isolation," Microwave and Optical Technology Letters, vol. 57, no. 2, pp. 322-324, 2015. 
[4] A. K. Agrawal and G. F. Mikucki, "A printed circuit hybrid ring directional coupler for arbitrary power divisions," IEEE Transactions on Microwave Theory and Techniques, vol. 34, no. 12, pp. 1401-1407, 1986.

[5] H. R. Ahn, I. Wolff, and I. S. Chang, "Arbitrary termination impedances, arbitrary power division and small-sized ring hybrids," IEEE Transactions on Microwave Theory and Techniques, vol. 44, no. 12, pp. 2241-2247, 1997.

[6] H. R. Ahn and I. Wolff, "Three-port 3-dB power divider terminated by different impedances and its application to MMICs," IEEE Transactions on Microwave Theory and Techniques, vol. 47, no. 6, pp. 786-794, 1999.

[7] K. K. M. Cheng and P. W. Li, "A novel power-divider design with unequal power-dividing ratio and simple layout," IEEE Transactions on Microwave Theory and Techniques, vol. 57, no. 6, pp. 1589-1594, 2009.

[8] P. W. Li and K. K. M. Cheng, "A new unequal power-divider design with enhanced insertion loss flatness," IEEE Microwave and Wireless Components Letters, vol. 19, no. 12, pp. 786-788, 2009.

[9] Z. Haiwei and X. Quan, "A novel Gysel power divider with arbitrary power ratio for high-power application," in Proceedings of IEEE International Wireless Symposium (IWS), Beijing, China, 2013, pp. 1-4.

[10] Y. Z. Zhu, X. F. Zhang, X. F. Wu, C. Li, and G. Y. Fang,

\section{Young-Chul Yoon}

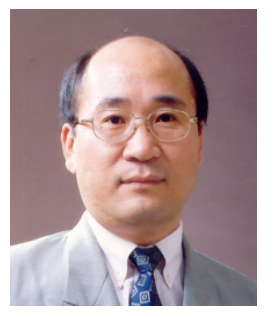

received his B.S., M.S., and Ph.D. in electronics engineering from Sogang University, Seoul, Korea, in 1978, 1982, and 1989, respectively. In 1987, he joined the Department of Electronics Engineering, Catholic Kwandong University, Gangneung, Korea, where he is currently a Professor. His areas of interest are the design of high power amplifiers for the ISM band, and RF and microwave circuit analysis and design.
"Novel Wilkinson power divider with uniform impedance line," in Proceedings of Asia-Pacific Microwave Conference (APMC), Macau, China, 2008, pp. 1-4.

[11] S. Horst, R. Bairavasubramanian, M. M. Tentzeris, and J. Papapolymerou, "Modified Wilkinson power dividers for millimeter-wave integrated circuits," IEEE Transactions on Microwave Theory and Techniques, vol. 55, no. 11, pp. 24392446, 2007.

[12] T. Qi, S. He, Z. Dai, and W. Shi, "Novel unequal power divider with $50 \Omega$ characteristic impedance lines," IEEE Microwave and Wireless Components Letters, vol. 26, no. 3, pp. 180-182, 2016.

[13] F. Lin, Q. X. Chu, and S. W. Wong, "A novel Gysel power divider design with uniform impedance transmission lines for arbitrary power-dividing ratios," Journal of Electromagnetic Waves and Applications, vol. 27, no. 2, pp. 242-249, 2013.

[14] M. J. Park and B. Lee, "Design of ring couplers for arbitrary power division with $50 \Omega$ lines," IEEE Microwave and Wireless Components Letters, vol. 21, no. 4, pp. 185-187, 2011.

[15] D. S. Eom and H. Y. Lee, "A broadband half-mode substrate integrated waveguide quadrature Wilkinson power divider using composite right/left-handed transmission line," Journal of Electromagnetic Engineering and Science, vol. 17, no. 1, pp. 9-13, 2017.

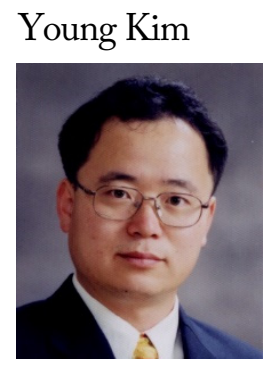

received his B.S., M.S., and Ph.D. in electronics engineering from Sogang University, Seoul, Korea, in 1986, 1988, and 2002, respectively. He developed cellular and PCS linear power amplifiers at Samsung Electronics Co., Ltd. In 2003, he joined the School of Electronics Engineering, Kumoh National Institute of Technology, Gumi, Korea, where he is currently a Professor. His areas of interest are the design of highpower amplifiers and linearization techniques, and RF and microwave circuit analysis and design. 